- MAU methodology allows assessments of both medical and non-medical factors

including outcomes of removal and retention of mandibular third molars.

- Patients' ranking of preferred outcomes was similar, regardless of country.

- Patients prefer outcomes of third molar non-removal as compared to outcomes following removal.

- Patient treatment preferences are more stable across national boundaries than dentist preferences.

\title{
Third molar treatment outcome: a comparison of patients' preferences in Sweden and Wales
}

\author{
R. Liedholm, ${ }_{1}$ K. Knutsson, ${ }_{1}^{2}$ L. Lysell, ${ }^{3}$ M. Rohlin, ${ }_{1}^{4}$ M. Brickley ${ }^{5}$ and J. Shepherd ${ }^{6}$
}

\begin{abstract}
Aim To elucidate and compare patients' outcome preferences for removal and retention of mandibular third molars in Sweden and Wales. Subjects and method The subjects comprised patients referred and scheduled for removal of one or both mandibular third molars in Sweden and Wales. The multi-attribute utility (MAU) methodology was applied to study patients' preferences for outcomes of removal and retention of the mandibular third molar.

Results Relative weighting of domains was similar in the two countries. 'Home and social life' received the highest relative weighting in Sweden and 'general health and wellbeing' in Wales. 'Your appearance' received the lowest relative weighting in both countries. In both Sweden and Wales operative jaw fracture was considered to be the outcome with most impact and dentigerous cyst and imbricated incisors the least impact. Outcome ranking was similar in both countries and operative outcomes were considered by patients to be more detrimental to health than retention outcomes.

Conclusions This comparison showed that patients' preferences in Sweden and Wales were similar and that the outcomes of surgery were considered worse after third molar removal than retention. Patientorientated treatment decisions were less subject to variation than clinician-orientated decisions.
\end{abstract}

\section{INTRODUCTION}

Evidence-based healthcare incorporates the "conscientious, explicit and judicious use of current best evidence in making decisions about the care of individual patients. ${ }^{1}$ This approach to healthcare encourages clinicians to interpret evidence on an individual patient basis and to include assessment of patient outcome preference in decision making. Patients' preferences in healthcare settings reflect many factors. It is increasingly appar-

\footnotetext{
${ }^{1 *}$ Consultant, Department of Oral Surgery and Oral Medicine, Faculty of Odontology, Malmö University, Malmö, Sweden: ${ }^{2}$ Associate Professor and ${ }^{4}$ Professor, Department of Maxillofacial and Oral Radiology, Faculty of Odontology, Malmö University; ${ }^{3}$ Associate Professor, Department of Oral and Maxillofacial Surgery, Central Hospital, Kristianstad, Sweden; ${ }^{5}$ Lecturer and ${ }^{6}$ Professor, Oral and Maxillofacial Surgery, Dental School, University of Wales College of Medicine, Cardiff, United Kingdom

${ }^{*}$ Correspondence to: Rolf Liedholm

Email:Rolf.Liedholm@od.mah.se
}

\section{Refereed paper}

Accepted 31 January 05

doi: $10.1038 /$ sj.bdj.4812653

(c) British Dental Journal 2005; 199: 287-291 ent that these are both medical and non-medical, and include social, cultural and economic factors. Whilst traditional utility assessment methods fail to integrate non-medical factors, ${ }^{2}$ multi-attribute utility (MAU) methodology, allows assessment of both medical and non-medical factors. ${ }^{3}$

With regard to the prophylactic removal of mandibular third molars, published research has focused on general dental practitioners' and oral surgeons' opinions about risks and benefits ${ }^{4,5}$ and patients' preferences concerning mandibular third molar removal and retention. ${ }^{6,7,8}$ In one of these studies, ${ }^{8}$ on Swedish patients' preferences, complications following removal were considered to have greater negative effects on their lives than complications of retention. It is not known whether this holds true across national boundaries.

The aim of this study was therefore to elucidate patients' preferences for outcomes of mandibular third molar removal and retention on an international basis. The study was done in Sweden and Wales, because comparisons of third molar treatment there had previously been carried out. There are, however, differences in the two countries in terms of costs and delivery: two major issues in national healthcare. In Sweden, all patients pay for third molar examination and surgical treatment while in the UK, National Health Service treatment is, apart from standard adult patient copayments in the general dental service, free at the point of delivery. Furthermore, the number of oral surgeons per million inhabitants is lower in the UK compared with Sweden. ${ }^{9}$ There is also a difference in practice pattern: large numbers of mandibular third molar removals are still done under general anaesthesia in the UK whereas in Sweden these numbers are very low.

It is possible that these differences affect patient treatment preferences, for example for removal or retention of third molars. It is also possible that preferences are shared across healthcare systems. Thus, the hypothesis that guided the research reported here was that patients' third molar outcome preferences relating to removal and retention of mandibular third molars in Sweden and Wales are similar when ranked using MAU methodology.

\section{SUBJECTS AND METHOD}

\section{Subjects}

The subjects comprised patients referred for removal of one or both mandibular third molars. In Sweden, patients were referred in $1997 / 8$ to three oral and maxillofacial surgery clinics of the 
Table 1 Sex and age (years) distribution of patients participating in the different stages of multi-attribute utility (MAU) study performed in Sweden and Wales. Within Stage 2 and Stage 3 there were differences $(P<0.05)$ in mean age between the Swedish and Welsh participants.

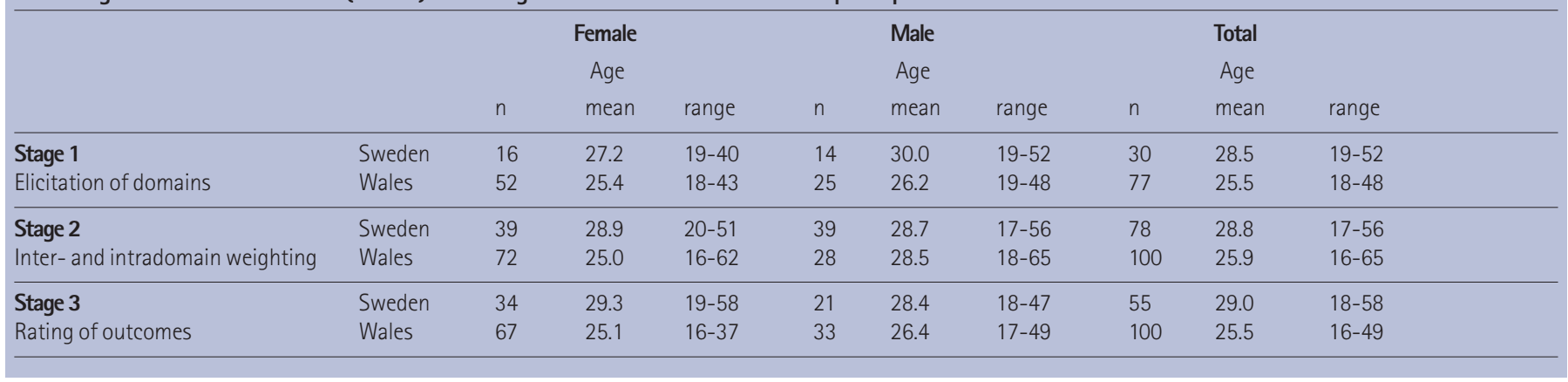

National Health Service in south Sweden. In Wales, patients were referred in 1997/8 to the department of oral and maxillofacial surgery, Dental Hospital, Cardiff. Patients who were scheduled for third molar surgical removal were recruited to the study. At the initial consultation, patients were fully informed about the nature, effects and probability of complications. No patient had previous experience of third molar removal. The sex and age distribution of the patients participating in the three stages of the study are presented in Table 1 . The difference between the mean age of the Swedish and Welsh participants was calculated by the t-test $(\mathrm{P}=0.05)$.

\section{The multi-attribute utility (MAU) method}

Multi-attribute utility assessment was in three stages:

Stage 1 Elicitation of domains (attributes), ie main areas of concern that patients considered important generally in their lives, which could be affected by mandibular third molar removal and retention.

Stage 2 Inter- and intradomain weighting. Interdomain weighting was done by relative weighting of the domains elicited in Stage 1. In the intradomain weighting, patients designated values for different health states. The health states were described as a decomposed function of each attribute.

Stage 3 Rating of outcomes. The patients were asked to imagine experiencing a series of representative outcomes of mandibular third molar removal and retention, which were described in a number of short descriptions (vignettes).

\section{Stage 1. Elicitation of domains}

\section{The interview}

The domains were elicited by means of an interview technique based on recommendations set out by Babbie. ${ }^{10}$ Interviews were performed by the four authors in Sweden and by a research assistant in Wales who had been trained to use this technique. The interviews were conducted separately by one interviewer, took place in the clinic immediately after the consultation and were tape-recorded. Thirty patients participated in Sweden and 77 took part in Wales.

The interviews were non-structured and included questions regarding medical, psychological, social, cultural and economic dimensions, to identify main areas of concern (domains) the patients thought could have an impact on their lives.

The interviewer started the interview with the question "what do you expect to experience after having your wisdom tooth out?' After taking cues from this response, further open-ended questions were asked if considered necessary. Examples of such questions were:

How do you feel about coming into hospital?

How do you feel about having time off from work/school?

What arrangements might you have to make before coming into hospital?

Is there anything specific that concerns you about the operation?
What do you feel about the complications which have been explained to you?

How do you think having the operation will affect your normal routine?

Which of the effects you have mentioned do you feel might affect you most?

How do you imagine having your tooth out may affect other areas of your life?

\section{Content analysis}

The tape recordings were then transcribed to preserve textual data. Then, the interviewer processed the textual data by searching for patients' statements which described 'areas of importance' that could influence their health state. Examples of statements that emerged were: 'I feel good about getting rid of the tooth. It is very difficult to keep it clean', and 'the effects of postoperative complications worry me. I do not worry about the operation'. Each statement was 'indexed' to identify categories of 'areas of importance'. Examples of such 'areas of importance' were 'to feel safe' or 'the operation/procedure'.

Then the 'areas of importance' were categorised into domains. Domains were defined as areas of common concern, interest or importance to the patients. Domains that were considered irrelevant and inconsistent with an MAU model concerning mandibular third molars were excluded. Such excluded domains were "physical integrity' and 'economic situation'.

In Wales the interviews were subjected to content analyses by the two UK authors (MB, JS). In Sweden the same procedure was performed by the four Swedish authors (RL, KK, LL, MR). The six authors in collaboration did the final categorisation into domains.

\section{Stage 2. Domain weighting}

\section{Interdomain weighting}

Samples of 78 further third molar patients in Sweden and 100 further patients in Wales were asked to weight the relative importance of the domains which emerged in Stage 1. They were asked to distribute 100 'resource points' to the domains, assigning a greater or lesser number of points (from 0 to 100) to the domains that they felt were more or less important to them. They were also allowed to reject any domain which they perceived would not be affected by the outcomes being considered.

\section{Intradomain weighting}

To each of the individual domains, four health states (see Table 3), representing a range of descriptions applicable to these domains, were constructed as described by Brickley et al. ${ }^{11}$ Values were then assigned to these health states by the 78 patients who took part in the interdomain weighting exercise. By placing the health states on a one hundred centimetre visual analogue scale (VAS) with numerical anchor points of 0 and 100, it was possible to obtain quantitative values for the health states. 
Thus, the patients were asked to mark their choices for 0 (worst) and 100 (best) on the VAS. Then, the patients were asked to place the remaining two health states on the scale between 0 and 100 . These two points were measured to the nearest $0.5 \mathrm{~cm}$. The difference between the mean weightings of the Swedish and the Welsh patients was calculated by the t-test $(\mathrm{P}=0.05)$.

\section{Stage 3. Rating of outcomes}

Eighteen vignettes describing outcomes of mandibular third molar removal and retention were constructed using evidence from the literature. ${ }^{12-20}$ A new sample of 55 patients in Sweden and 100 patients in Wales was asked to imagine experiencing the outcomes described in each vignette. Then, the patients were asked to select the health state within each of the five domains that matched how they imagined experiencing the outcomes described in each vignette. This was repeated for all 18 vignettes.

\section{Calculation of patients' preferences}

The results of patients' intra- and interdomain weightings were recorded as numerical data and were entered into a spreadsheet. The mean value of the domain weightings were then calculated using SPSS (Statistical Package for the Social Sciences).

The result derived for each vignette was expressed as "preference'. The preference for each vignette and each patient was calculated using the following formula:

$\mathrm{P}_{\text {total }=}\left(\sum \mathrm{P}_{\mathrm{d}} \mathrm{W}_{\mathrm{d}}\right): 100$

where

$\mathrm{P}_{\text {total }}$ The overall preference

$\mathrm{P}_{\mathrm{d}=}$ The value given to the intradomain health state that has

been derived from the intradomain weightings

$\mathrm{W}_{\mathrm{d}}=$ The interdomain weighting of a specific domain.

The mean preference was then calculated for each of the 18 vignettes. This was done separately for the patients in Sweden and Wales. A worked example is shown in the Appendix.

Ranking of mean values of the preferences was done for each country separately. Rank order in the two countries was compared using Spearman's rank correlation $(\mathrm{P}=0.05)$.

\section{Patient-reliability and understanding of the method}

Patient-reliability and understanding of the method for interdomain and intradomain weighting were tested in Sweden and have previously been reported. ${ }^{8}$ The results justified the application of MAU methodology to mandibular third molar removal and retention.

\section{RESULTS}

\section{Elicitation of domains}

Based on the non-structured interviews of patients in Sweden and Wales five domains were identified, ie 'home and social life', 'general health and well-being', 'job and studies', 'health and comfort of mouth, teeth and gums' and 'your appearance'.

\section{Domain weighting}

The patients' interdomain weightings are presented in Table 2. The mean weighting of the relative importance was highest in Sweden for 'home and social life', while 'general health and well-being' was highest in Wales. 'Job and studies' was rated as the third most important weighting in Sweden and 'health and comfort of mouth, teeth and gums' in Wales. 'Your appearance' received the lowest mean weighting in Sweden and 'job and studies', the lowest mean weighting in Wales.

The patients' intradomain weightings are presented in Table 3. The mean weightings of the second 'best' health state differed from the mean weightings of the second 'worst' health state for all domains. Weighting was different $(\mathrm{P}<0.05)$ for only three health
Table 2 Interdomain weighting. Mean and standard deviation(s) of the relative importance of the elicited domains as assigned by patients from Sweden $(n=78)$ and Wales $(n=100)$ referred for mandibular third molar removal

\begin{tabular}{lllll}
\hline Domain & \multicolumn{2}{c}{ Sweden } & \multicolumn{2}{c}{ Wales } \\
& Mean & s & Mean & s \\
\hline Home and social life & 26.6 & 7.0 & 20.7 & 8.5 \\
General health and well-being & 25.9 & 7.3 & 24.7 & 8.0 \\
Job and studies & 20.4 & 6.6 & 15.8 & 8.1 \\
Health and comfort of mouth, & 18.3 & 5.0 & 19.9 & 7.7 \\
teeth and gums & & & & \\
Your appearance & 8.8 & 6.3 & 18.6 & 8.4 \\
& & & &
\end{tabular}

Table 3 Intradomain weighting. Mean and standard deviation (s) expressed in $\mathrm{cm}$ VAS ( 0 represents 'worst' health state and 100 'best' health state on the VAS) as assigned by patients from Sweden $(n=78)$ and Wales $(n=100)$ referred for mandibular third molar removal

\section{Domains and Health states}

$\begin{array}{lll}\text { Sweden } & & \text { Wales } \\ \text { Mean } & s & \text { Mean }\end{array}$

\section{Home and social life}

My home and social life is unaffected. 100

My home and social life is affected

as usual

My home and social life is seriously

affected. I cannot enjoy life as much

as usua

My home and social life is completely 0

disrupted. I do not enjoy life as much at all

\section{General health and well-being}

I feel really good, well and relaxed.

I am not worried about my health

I feel fairly well in myself. I am not

worried or anxious about my health

I do not feel especially well.

I feel a bit anxious about my health

I do not feel well at all.

100

I feel very anxious about my health

\section{Job and studies}

My job and studies are unaffected. $\quad 100$

My job and studies are slightly affected 72.3

**My job and studies are affected $\quad 39.6$

to a moderate extent

My job and studies are seriously affected 0

Health and comfort of mouth, teeth and gums

My mouth feels really healthy and my 100

teeth and gums are comfortable.

I can eat and talk normally

My mouth feels fairly healthy and my $\quad 67.1$

teeth and gums are comfortable.

I can eat and talk almost normally

My mouth, teeth and gums do not feel 24.6

very healthy. It is affecting my eating to

a moderate extent

My mouth does not feel healthy at all. 0

Speaking and eating are difficult

\section{Your appearance}

My face looks norma 
states, which were weighted lower by patients in Wales compared with patients in Sweden. In particular, patients in Wales considered that their job and studies, and their appearance would be affected to a greater extent than patients in Sweden.

\section{Patients' preferences for the vignettes}

Table 4 presents the mean patients' preferences and the ranking of the outcomes described in the vignettes. There was a high degree of correlation in patients' ranking of the different outcomes between the two countries ( $r s=0.93, \mathrm{P}<0.001$ ).

Generally, vignettes describing the outcomes of retention attracted higher ranking, ie had least impact, than vignettes describing the outcomes of surgical removal. Vignette 18, which described the presence of a fluid-filled sac which suggested that this tooth must be removed, received the highest ranking, i.e had the least impact in Sweden. In Wales vignette 17, which described the lower front teeth as 'more squashed together' received the highest ranking*. Symptoms of mild transient pericoronitis (vignette 13) received the second highest ranking by patients in both countries. 'After the extraction, the surgeon tells you that your jaw is broken and...' (vignette 12) received the lowest ranking by patients, in both countries. The second lowest ranking was achieved by vignettes that described severe pain (vignette 2) and permanent numbness of the lip and tongue (vignette 11), but in reverse order in the two countries.

*Note that the evidence is that third molars have, in fact, little or no effect on incisor crowding.

\section{DISCUSSION}

The principal finding of this study, and the most important for practitioners and healthcare managers, is that patient-orientated decisions were very consistent across national boundaries. This underlines the importance of taking fully into account, in a systematic and organised manner, the beliefs of patients in decisions about their care. Standard gamble, time trade-off, MAU, rating-scales, magnitude estimation, equivalence and willingness to pay methods and most scaling methods are all considered credible for this purpose. ${ }^{21}$ The MAU technique allows quantification and incorporation of social, psychological and physical components of health states into utility measurement and allows clinicians and patients alike to focus on the critical issues in reaching a treatment decision. The vignettes were constructed to illustrate a wide variety of outcomes of removal and retention of third molars and both temporary and chronic outcomes, to reflect a range of outcomes which might be expected to affect patients' quality of life over a lifetime. Long term outcomes could be expected to affect patients to a greater degree than transient outcomes.

The selection of patients in Sweden and Wales was somewhat different. In both countries, general dental practitioners referred the patients and some patients in Wales were referred from the hospital examination and emergency department. The population of patients was randomly selected and is representative of the population referred for third molar removal. Not all of them had problems with their third molars. Of those referred for removal, in both Sweden and Wales, about one fifth were without any symptoms and pathology. Patient distribution according to age was about equal between the two countries, even though statistically significant differences in age existed in Stage 2 and Stage 3. However, these mean differences were about three years: the Swedish participants were a few years older compared with the Welsh patients. The impact of this limited age difference on the overall result must be considered to be minor. However, the distribution of females and males differed. In Sweden, gender distribution was equal in

Table 4. Patients' preferences. Mean and ranking (R) of 18 vignettes within each country separately. The preferences were based on Swedish ( $n=55)$ and Welsh ( $n=100)$ patients' ratings when asked to imagine experiencing the outcomes of the vignettes. Ranking 1 represents the least annoying and ranking 18 the most annoying outcome. There was a high degree of correlation between he two countries $(r s=0.93, P<0.001)$

\begin{tabular}{|c|c|c|c|c|}
\hline Vignette & \multicolumn{2}{|c|}{ Sweden } & \multicolumn{2}{|c|}{ Wales } \\
\hline & Mean & $\mathrm{R}$ & Mean & $\mathrm{R}$ \\
\hline 1. After the extraction you experience moderate pain and your face and mouth are very swollen & 51.7 & 11 & 15.5 & 10 \\
\hline 2. After the extraction you experience severe pain which keeps you awake for a few nights & 37.3 & 17 & 38.8 & 16 \\
\hline 3. After the extraction your jaw is stiff and painful. You have difficulty opening your mouth as wide as normal & 55.9 & 9 & 43.5 & 15 \\
\hline 4. After the extraction you experience minor discomfort and abnormal bleeding from the socket for a few hours & 60.8 & 7 & 56.2 & 9 \\
\hline $\begin{array}{l}\text { 5. After the extraction you experience minor discomfort and also tingling and prickling sensations in your lower lip } \\
\text { or tongue for up to two weeks }\end{array}$ & 56.3 & 8 & 59.9 & 7 \\
\hline 6. After the extraction you have minor discomfort. Your tongue is completely numb on one side for up to six weeks & 50.5 & 12 & 52.5 & 11 \\
\hline 7. After the extraction you have minor discomfort. Your tongue is completely numb on one side permanently & 44.1 & 14 & 46.1 & 13 \\
\hline $\begin{array}{l}\text { 8. After the extraction you have minor discomfort. Your lower lip (but not your tongue) is completely numb on one } \\
\text { side for up to six weeks }\end{array}$ & 55.0 & 10 & 56.9 & 8 \\
\hline $\begin{array}{l}\text { 9. After the extraction you have minor discomfort. Your lower lip (but not your tongue) is completely numb on one } \\
\text { side permanently }\end{array}$ & 48.2 & 13 & 49.2 & 12 \\
\hline $\begin{array}{l}\text { 10. After the extraction you have minor discomfort Your lower lip and your tongue are completely numb on one side } \\
\text { for up to six weeks }\end{array}$ & 42.8 & 15 & 45.9 & 14 \\
\hline $\begin{array}{l}\text { 11. After the extraction you have minor discomfort. Your lower lip and your tongue are completely numb on one side } \\
\text { permanently }\end{array}$ & 40.5 & 16 & 38.3 & 17 \\
\hline $\begin{array}{l}\text { 12. After the extraction the surgeon tells you that your jaw is broken and that you need your teeth wired together for } \\
\text { up to four weeks }\end{array}$ & 35.9 & 18 & 15.5 & 18 \\
\hline $\begin{array}{l}\text { 13. A tooth comes up at the back of your mouth. On one occasion this gives you a few days of aching pain and around } \\
\text { the tooth the gum is swollen }\end{array}$ & 85.0 & 2 & 78.8 & 2 \\
\hline $\begin{array}{l}\text { 14. A tooth comes up at the back of your mouth. Every six weeks or so you experience a few days of aching pain and } \\
\text { around the tooth the gum feels swollen }\end{array}$ & 73.8 & 5 & 70.4 & 3 \\
\hline 15. The position of the wisdom tooth causes 'gum disease' in the tooth in front which will make losing it more likely & 71.8 & 6 & 64.9 & 6 \\
\hline $\begin{array}{l}\text { 16. You have a new tooth, which comes up, behind your last lower tooth. This results in the tooth in front becoming } \\
\text { decayed and needing extraction }\end{array}$ & 82.7 & 4 & 68.5 & 5 \\
\hline $\begin{array}{l}\text { 17. You notice that the appearance of your lower front teeth has changed slightly. The teeth appear to be more } \\
\text { 'squashed' together }\end{array}$ & 83.7 & 3 & 80.5 & 1 \\
\hline $\begin{array}{l}\text { 18. After having an X-ray to find out if your wisdom tooth is present, the dentist tells you that there is a fluid-filled sac } \\
\text { around your wisdom tooth and that this tooth must be removed }\end{array}$ & 85.1 & 1 & 69.6 & 4 \\
\hline
\end{tabular}


Stages 1 and 2. In Stage 3 more females participated. In Wales, however, females outnumbered males by about $2: 1$ in all three stages, reflecting treatment demand. Even though there were differences in gender distribution between the countries, this did not appear to influence the domains which were elicited. Main areas of concern identified were the same in both countries. However, in Stage 2, in which patients assessed the relative importance of the domains, interdomain weighting, some differences emerged, which may, in part reflect differing proportions of females/ males participating together with cultural differences. For example, the domain 'home and social life' was assigned the highest value in Sweden while 'general health and well-being' was assigned the highest value in Wales.

Most importantly, this study demonstrated consistent patient values with regard to the outcome of third molar treatment decisions in two contrasting European cultures. Patients in Sweden and Wales believed that the impact of third molar removal would have a more negative effect on their lives than the impact of retention: patients generally preferred a more restrictive approach to intervention. In contrast, dentists are known to have different attitudes towards potential outcomes of different treatment alternatives. ${ }^{22,23}$ A recent study compared general dental practitioners' third molar removal rates in Sweden and Wales, ${ }^{5}$ and found no significant difference between mean number of third molars scheduled for removal in the two countries. However, Swedish oral surgeons scheduled significantly more third molars for removal than oral surgeons in Wales. ${ }^{5}$ Although differences in socio-economic contexts from the perspective of family dentists and oral surgeons in Sweden as compared with Wales might contribute to this difference, a more likely explanation is a lively public debate about reasons for removal in the UK, starting in the early 1990s. Differences in access to oral surgeons (these are almost double the number in Sweden compared with UK despite a much lower population), and anesthetic provision may also play a part. However, even though these differences exist from the professional perspective they have not, according to the results in this study, affected patients' preferences on this issue either in Sweden or in Wales. Again, this strengthens the case for adopting a much more patient-orientated, less clinician-orientated approach to decision making.

In conclusion, these results are in accordance with our hypothesis: despite differences in healthcare delivery in the two countries, the main areas of importance in patients' lives that could be influenced by retention or removal of mandibular third molars were similar. Furthermore, preferences for the various outcomes of these two treatment alternatives were also consistent.

1. Sackett $D$ L, Rosenberg W M, Gray J A, et al. Evidence based medicine: what it is and what it isn't. BrMed J 1996: 312: 71-72.

2. Keeny R, Raiffa H. Decisions with multiple objectives: preferences and value tradeoffs. New York: John Wiley, 1976.

3. Torrance G W, Boyle M H, Horwood S P. Application of multiattribute utility theory to measure social preferences for health states. Oper Res 1982; 30: 1043-1069.

4. Knutsson K, Brehmer B, Lysell L, et al. General dental practitioners' evaluation of the need for extraction of asymptomatic mandibular third molars. Community Dent Ora Epidemiol 1992; 20: 347-350

5. Knutsson K, Brehmer B, Lysell L, et al. Asymptomatic mandibular third molars: oral surgeons' judgement of the need for extraction. J Oral Maxillofac Surg 1992; 50: 329-333.

6. Brickley M, Kay E, Shepherd J P, et al. Decision analysis for lower-third-molar surgery. Med Decis Making 1995; 15: 143-151.

7. Armstrong RA, Brickley MR, Evans DJ, et al. Patient perceptions regarding the risks of complications of lower third molar removal. Community Dent Health 1996; 13: 17-21.

8. Liedholm $R$, Knutsson $K$, Lysell $L$, et al. The outcomes of mandibular third molar removal and non-removal: a study of patients' preferences using a multi-attribute method. Acta Odonto/ Scand 2000; 58: 293-298.

9. Worrall S F, Riden $K_{1}$ Haskell R, et al. UK National third molar project: the initial report Br J Oral Maxillofac Surg 1998; 36: 14-18.

10. Babbie E. The practice of social research. 6th ed. Belmont (Ca): Wadsworth Publishing Company, 1992
11. Brickley $M$, Armstrong $R$, Shepherd J, et al. The relevance of health state utilities to lower third molar surgery. Int Dent J 1995; 45: 124-128.

12. Van Gool A V, Ten Bosch J J, Boering G. Clinical consequences of complaints and complications after removal of the mandibular third molar. Int J Oral Surg 1977; 6: 29-37.

13. Nordenram $\AA$. Postoperative complications in oral surgery. A study of cases treated during 1980. Swed Dent J 1983; 7: 109-113.

14. Osborn T P, Frederickson G Jr, Small I A, et al. A prospective study of complications related to mandibular third molar surgery. J Oral Maxillofac Surg 1985; 43: 767-769.

15. Sisk A L, Hammer W B. Shelton D W, et al. Complications following removal of impacted third molars: the role of the experience of the surgeon. J Oral Maxillofac Surg 1986; 44: 855-859.

16. Mercier P. Precious D. Risks and benefits of removal of impacted third molars. $J$ Oral Maxillofac Surg 1992; 21: 17-27.

17. Stanley H R, Alattar M, Collett W K, et al. Pathological sequelae of 'neglected' impacted third molars. J Oral Pathol 1988; 17: 113-117.

18. Eliasson $S$, Heimdal A, Nordenram $\AA$. Pathological changes related to long-term impaction of third molars. A radiographic study. Int J Oral Maxillofac Surg 1989; 18: 210-212.

19. Von Wowern $\mathrm{N}$, Nielsen $\mathrm{H} \mathrm{O}$. The fate of impacted lower third molars after the age of 20. A four-year clinical follow-up. Int J Oral Maxillofac Surg 1989; 18: 277-280.

20. Ahlqwist M, Gröndahl H G. Prevalence of impacted teeth and associated pathology in middle-aged and older Swedish women. Community Dent Oral Epidemiol 1991; 19: 116-119.

21. Boyle M H, Torrance G W. Developing multiattribute health indexes. Med Care 1984; 22: 1045-1057.

22. Liedholm R, Knutsson $\mathrm{K}$, Lysell $\mathrm{L}$, et al. Mandibular third molars: oral surgeons assessment of the indications for removal. Br J Oral Maxillofac Surg 1999; 37: 440-443.

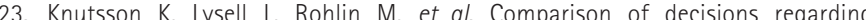
prophylactic removal of mandibular third molars in Sweden and Wales. Br Dent J 2001; 190: 198-202.

\section{APPENDIX}

Example of the calculations for one patient and vignette 1: 'After the extraction you experience moderate pain and your face and mouth are very swollen'. The patient selected the following health states within each domain that matched how she imagined experiencing the outcomes described in vignette 1 .

\begin{tabular}{llll} 
Domain & $\begin{array}{l}\text { Health states } \\
\text { selected by } \\
\text { the patient }\end{array}$ & $\begin{array}{l}\text { Intradomain } \\
\text { weighting }\end{array}$ & $\begin{array}{l}\text { Interdomain } \\
\text { weighting }\end{array}$ \\
\hline $\begin{array}{l}\text { Home and social life } \\
\text { General health and }\end{array}$ & $\begin{array}{l}\text { Seriously affected } \\
\text { Do not feel }\end{array}$ & 30.5 & 31 \\
$\begin{array}{l}\text { well-being } \\
\text { Job and studies }\end{array}$ & $\begin{array}{l}\text { Slightly affected } \\
\text { Do not feel }\end{array}$ & 68.5 & 27 \\
$\begin{array}{l}\text { Health and comfort of } \\
\text { mouth, teeth and gums }\end{array}$ & $\begin{array}{l}\text { very healthy } \\
\text { Quite normal }\end{array}$ & 75.5 & 14 \\
Your appearance & & & 24 \\
& & &
\end{tabular}

The preference $(\mathrm{P})$ for this patient and vignette 1 would be:

$\mathrm{P}=$ (intradomain weighting for home and social life $\mathrm{x}$ interdomain weighting for home and social life) + etc 100

$P=\frac{(30.5 \times 31)+(27.0 \times 27)+(68.5 \times 24)+(19.5 \times 14)+(75.0 \times 4)}{100}$

$P=\frac{945.5+729+1644+273+300}{100}$

$\mathrm{P}=\underline{3891.5}$

100

$\mathrm{P}=38.9$ 